\title{
UJI EKSPERIMENTAL MESIN PENDINGIN BERPENDINGIN COOLANT DENGAN MENGGUNAKAN REFRIGERAN R22 DAN REFRIGERAN R407C
}

\author{
Fransiskus Xaverius Phie ${ }^{1)}$, Harto Tanujaya) ${ }^{1)}$ dan Steven Darmawan ${ }^{2)}$ \\ Program Studi Teknik Mesin Universitas Tarumanagara, Jakarta \\ e-mail : Frushxx@yahoo.com
}

\begin{abstract}
Abstrak: Salah satu penyebab kerusakan lapisan ozon adalah zat pendingin. Kandungan zat pendingin akan terurai setelah dicampur dengan sinar ultraviolet. Itu juga molekul refrigeran yang tepat yang melepaskan atom klorin. Klorin yang dikeluarkan akan menghancurkan lapisan ozon dan tingkat sinar ultraviolet yang masuk ke bumi yang lebih tinggi. Tapi tidak semua jenis zat pendingin mengandung klorin. Jenis zat pendingin yang biasa digunakan pada pendingin mesin adalah R22. Refrigeran mengandung unsur klorin sehingga perlu memeriksa penggantian refrigeran $R 22$. Jenis zat pendingin yang memiliki kesamaan namun tidak mengandung unsur klorin adalah zat pendingin R407c. Penelitian dilakukan dengan mengambil beberapa data dari kedua jenis refrigerant tersebut. Tujuan dari penelitian ini adalah untuk menghitung laju kondensor perpindahan panas, kompresor pendingin, kapasitas daya dan koefisien kinerja setiap refrigeran. Penelitian dimulai dengan belajar tentang siklus kompresi uap, komponen utama dari pendingin mesin, sifat refrigeran, dan konsep pendinginan. Pengambilan data tekanan, suhu, dan arus listrik kuat berdasarkan debit 20 liter / jam, 40, 80, dan 120. Air pendingin kondensor menggunakan jenis pendingin, air dan udara. Data yang telah diambil akan dihitung dengan menggunakan rumus sistem pendingin. Pada refrigeran air dingin berpendingin pendingin R22 dengan koefisien perfomance lebih besar dari R407c. Pada nilai alir 40 l / h R22 adalah 6,58
\end{abstract}

Kata Kunci: Refrigeran, klorin, koefisien kinerja, dan efisiensi

\begin{abstract}
One of the causes of damage to the ozone layer is the refrigerant. Content of the refrigerant will unravel after mixed with ultraviolet light. It was also timely refrigerant molecules releasing chlorine atoms. Chlorine released would destroy the ozone layer and the level of ultraviolet rays that enter the Earth's higher. But not all types of refrigerant containing chlorine. Types of refrigerant are commonly used on the engine coolant is R22. Refrigerant contains elements of chlorine so it needs to examine the replacement of refrigerant $R 22$. Type of refrigerant which has similarities but does not contain the element chlorine is refrigerant R407c. Research done by taking some of the data from both types of refrigerant. The purpose of this study was to calculate the rate of heat transfer condenser, refrigeration compressor, power capacity and coefficient of performance of each refrigerant. Research begins with learning about steam compression cycle, the main components of the engine coolant, the properties of the refrigerant, and the concept of cooling. Data capture of pressure, temperature, and powerful electric current based on 20 liters/hour flowrate, 40, 80, and 120. Condenser cooling water using kind of coolant, water and air. Data which have been taken will be calculated using the formula of the cooling system. On refrigerant $R 22$ refrigerated water coolant of the coefficient of perfomance is larger than $R 407 c$. On 40 $l / h$ flowrate values of $R 22$ is 6,58 COP while the value of the cop R407c is 1,92. So the refrigerant $R 22$ refrigerant on more efficient than $R 407 c$.
\end{abstract}

Keywords: Refrigerant, chlorine, coefficients of performance, and efficiency

\section{PENDAHULUAN}

Mesin pendingin pada saat ini semakin banyak dimanfaatkan sesuai dengan kemajuan teknologi dan meningkatnya taraf hidup. Penggunaan yang umum adalah untuk mengawetkan makanan. Pada suhu biasa (suhu kamar) makanan cepat menjadi busuk (karena pada temperatur biasa bakteri akan berkembang cepat). Sedangkan pada suhu $4,4{ }^{\circ} \mathrm{C}$ atau $40{ }^{\circ} \mathrm{F}$ (suhu yang biasa untuk pendinginan makanan), bakteri berkembang sangat lambat sehingga makanan akan lebih tahan lama. Jadi disini makanan dapat diawetkan dengan cara mendinginkannya. Kegunaan lain dari mesin pendigin adalah penyejuk ruangan, pendingin minuman, membuat es batu, dan lain-lain. Pada kendaraan pengangkut daging/sayuran/ikan ke tempat-tempat yang jauh dilengkapi dengan mesin pendingin agar tidak busuk sampai di tempat tujuan. Untuk terjadinya suatu proses pendinginan diperlukan suatu bahan (refrigerant) yang mudah dirubah bentuknya dari gas menjadi cair atau dari cair ke gas untuk mengambil panas dari evaporator dan membuangnya di kondensor.

Kebanyakan refrigeran yang digunakan adalah refrigeran dengan jenis clorofluorocarbon (CFC) yang tidak ramah terhadap lingkungan. Sehingga para pakar lingkungan hidup semakin 
gencar memikirkan tentang penipisan lapisan ozon yang dirusak oleh gas-gas klorine yang dilepaskan manusia maupun melalui proses alami. Bahan perusak ozon merupakan turunan dari senyawa klor dan bahan karbon seperti clorofluorocarbon (CFC), banyak digunakan oleh industri maupun dalam rumah tangga. Alat refrigerasi seperti mesin pendingin ruangan (air conditioner) dan lemari es juga masih menggunakan R22, yang dapat merusak lapisan ozon jika terlepas ke udara. $\mathrm{R} 22\left(\mathrm{CHF}_{2} \mathrm{Cl}\right)$, refrigerant ini digunakan pada mesin freezer dan sebagainya yang menghendaki temperatur yang lebih rendah. Titik didihnya $-40^{\circ} \mathrm{C}$. Panas penguapan per jumlah refrigerant sedikit lebih baik dibanding dengan R12.

Oleh sebab itu, diperlukan pengganti refrigran yang memiliki sedikit perbedaan agar tidak mengkontaminasi spare part mesin pendingin dan ramah lingkungan (tidak merusak lapisan ozon). Refrigran R22 memiliki persamaan dengan refrigeran substitusi R407C. Refrigerant R407C merupakan campuran azeotrop antara $\mathrm{R} 32\left(\mathrm{CH}_{2} \mathrm{~F}_{2}\right) / \mathrm{R} 125\left(\mathrm{C}_{2} \mathrm{HF}_{5}\right)$ / $\mathrm{R} 134 \mathrm{~A}\left(\mathrm{C}_{2} \mathrm{H}_{2} \mathrm{~F}_{4}\right)$ dengan komposisi 23/25/52.

Berdasarkan pembahasan latar belakang diatas maka penulis memilih judul skripsi : 'Uji Eksperimental Mesin Pendingin Berpendingin Coolant dengan Menggunakan Refrigerant R22 dan Refrigerant Substitusi R407C'

\section{Perumusan Masalah}

Melakukan eksperimen untuk mendapatkan nilai efek refrigerasi, daya kompresor dan koefisien perfoma menggunakan refrigerant R22 dan R407C dengan kondensor berpendingin coolant.

\section{Kajian Pustaka}

Refrigerasi adalah produksi atau pengusahaan dan pemeliharaan tingkat suhu dari suatu bahan atau ruangan pada tingkat yang lebih rendah dari pada suhu lingkungan atau atmosfer sekitarnya dengan cara penarikan atau penyerapan panas dari bahan atau ruangan tersebut.

Prinsip dasar dari refrigerasi mekanik adalah proses penyerapan panas dari dalam suatu ruangan berinsulasi tertutup kedap lalu memindahkan serta mengenyahkan panas keluar dari ruangan tersebut. Proses merefrigerasi ruangan tersebut perlu tenaga atau energi. Energi yang paling cocok untuk refrigerasi adalah tenaga listrik yaitu untuk menggerakkan kompresor pada unit refrigerasi.

Dalam suatu sistem refrigrasi mekanik, berlangsung beberapa proses fisik yang sederhana. Jika ditinjau dari segi termodinamika, seluruh proses perubahan itu terlibat tenaga panas, yang dikelompokkan atas panas laten penguapan, panas sensibel, panas laten pengembunan dan lain sebagainya. suatu siklus refrigrasi secara berurutan berawal dari pemampatan, melalui pengembunan (kondensasi), pengaturan pemuaian dan berakhir pada penguapan (evaporasi).

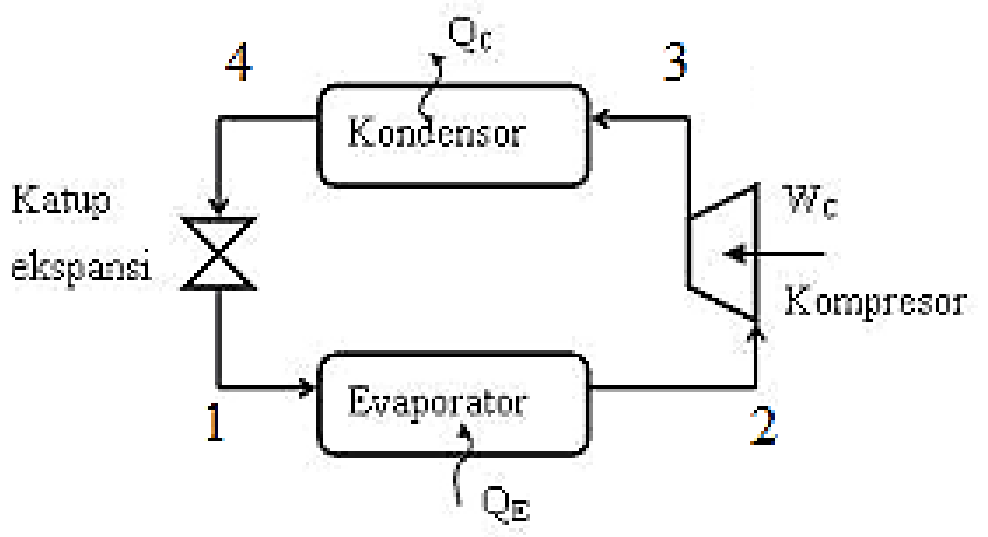

Gambar 1. Komponen mesin pendingin. 
Tabel 1. Perbandingan spesifikasi refrigerant R22 dengan refrigerant R407C

\begin{tabular}{lcc}
\hline Physical Properties & R407C & R22 \\
\hline Molecular Wt $(\mathrm{g} / \mathrm{mol})$ & 86.2 & 86.5 \\
\hline Vapor Density $(\mathrm{kg} / \mathrm{m} 3)$ & 42.0 & 44.2 \\
\hline Liquid Density $(\mathrm{kg} / \mathrm{m} 3)$ & 1134 & 1195 \\
\hline Boiling Point $\left({ }^{\circ} \mathrm{C}\right)$ & -37.1 to -44.3 & -40.8 \\
\hline Latent Heat Vap $(\mathrm{kJ} / \mathrm{kg})$ & 245 & 234 \\
\hline Ozone Depletion Potential & 0.00 & 0.05 \\
\hline Global Warming Potential & 1600 & 1700 \\
\hline
\end{tabular}

Selain persamaan sifat antara kedua refrigerant diatas, refrigerant R407C juga mengandung 3 unsur campuran R32 (23\%), R125(25\%), dan R134a(52\%).

\section{METODOLOGI PENELITIAN}

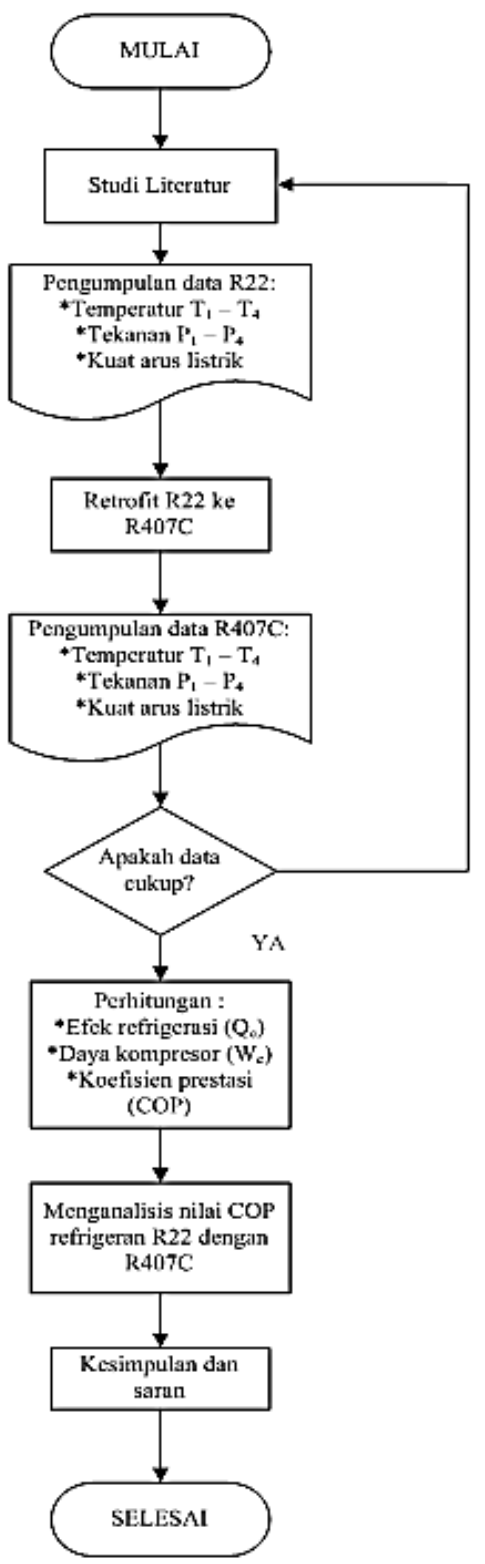

TIDAK

Gambar 2. Diagram Alir Pengerjaan Skripsi 


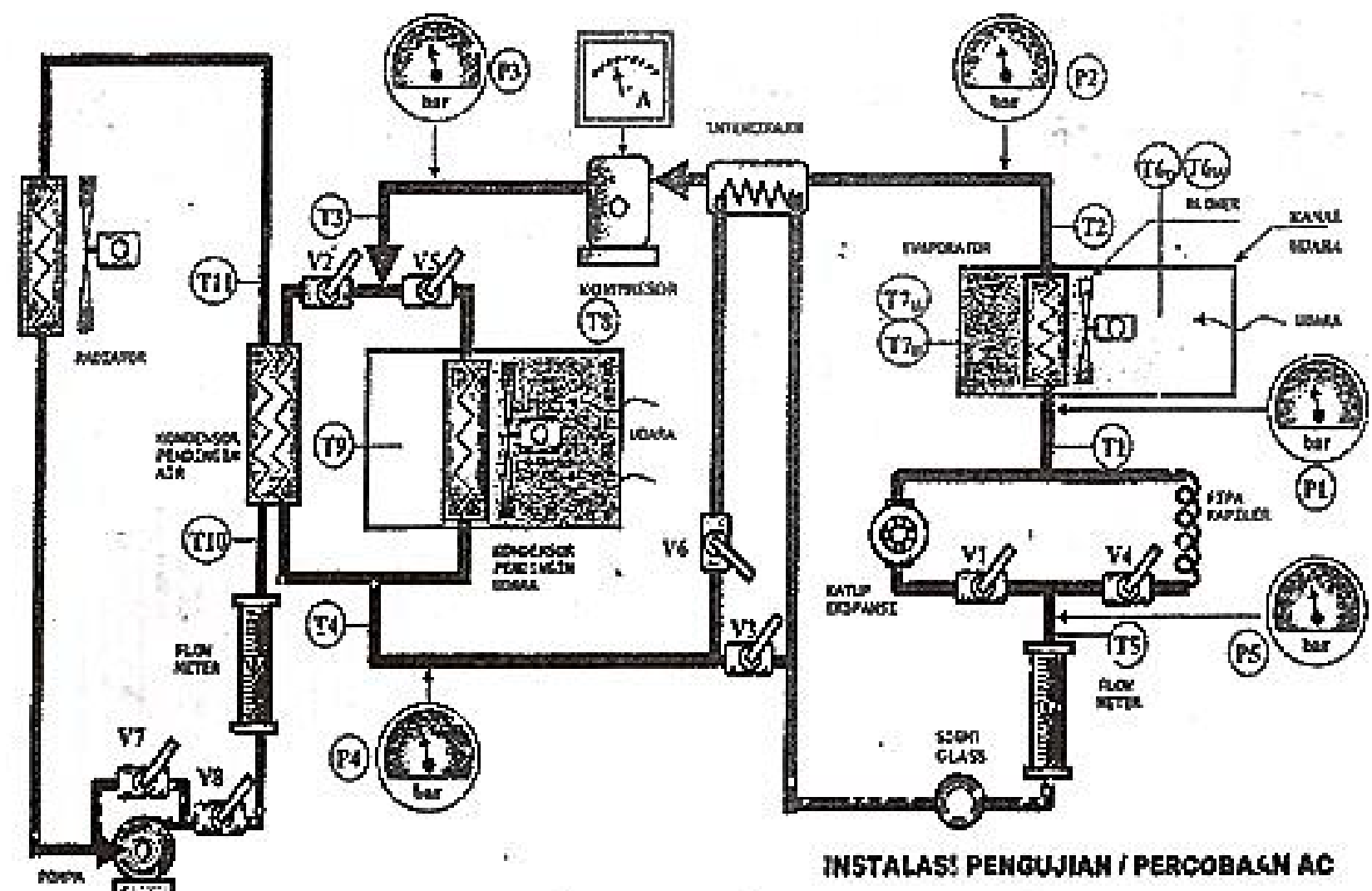

Gambar 3. Instalasi Sistem Mesin Pendingin

Penelitian ini menggunakan mesin pendingin di Laboratorium Perpindahan Panas dan Massa Universitas Tarumanagara. Skema instalasi sistem mesin pendingin tersebut dapat dilihat seperti pada Gambar 3.

Dalam penyusunan skripsi ini, dilakukan pengolahan data dengan melakukan perhitungan dari data-data yang telah didapatkan melalui uji eksperimental dengan menggunakan persamaan di bawah ini:

a. Besarnya laju perpindahan panas pada evaporator atau kapasitas refrigerasi (Qe)

$$
\dot{Q}_{e}=\dot{m}_{r}\left(h_{2}-h_{1}\right)
$$

b. Daya masukan kompresor (Wc)

$$
\dot{W}_{c}=\dot{m}_{r}\left(h_{3}-h_{2}\right)
$$

c. Koefisien prestasi (COP)

$$
C O P=\left(\frac{\dot{Q}_{e}}{\dot{W}_{c}}\right)=\left(\frac{\dot{m}_{r}\left(h_{2}-h_{1}\right)}{\dot{m}_{r}\left(h_{3}-h_{2}\right)}\right)=\frac{\left(h_{2}-h_{1}\right)}{\left(h_{3}-h_{2}\right)}
$$

Keterangan :

$\dot{m}_{r}$ : besarnya laju aliran refrigeran yang dialirkan per satuan detik.

h : nilai entalpi.

$\dot{Q}_{e} \quad$ : kapasitas refrigerasi yang dihasilkan oleh mesin pendingin.

$\dot{W}_{c}$ : besarnya daya kompresor yang dibutuhkan untuk mengompres refrigeran.

COP : besarnya nilai koefisien peforma yang dihasilkan oleh mesin pendingin. 


\section{HASIL DAN PEMBAHASAN}

Hasil perhitungan yang telah dilakukan dapat dilihat pada tabel di bawah:

Tabel 2. Hasil perhitungan R22.

\begin{tabular}{|c|c|c|c|c|c|c|c|}
\hline \multirow{2}{*}{$\begin{array}{c}\text { Flowrate } \\
\text { (L/h) }\end{array}$} & \multicolumn{4}{|c|}{ Entalpi (kJ/kg) } & \multirow{2}{*}{$\begin{array}{c}\text { Efek } \\
\text { refrigerasi } \\
\mathrm{m}_{\mathrm{r}}\left(\mathrm{h}_{2}-\mathrm{h}_{1}\right)\end{array}$} & \multirow{2}{*}{$\begin{array}{c}\text { Daya } \\
\text { kompresor } \\
\mathrm{m}_{\mathrm{r}}\left(\mathrm{h}_{3}-\mathrm{h}_{2}\right)\end{array}$} & \multirow[b]{2}{*}{$\mathrm{COP}$} \\
\hline & $\mathrm{h}_{1}$ & $\mathrm{~h}_{2}$ & $\mathrm{~h}_{3}$ & $\mathrm{~h}_{4}$ & & & \\
\hline 20 & - & - & - & - & - & - & - \\
\hline 40 & 76 & 267 & 296 & 76 & 2,48 & 0,37 & 6,58 \\
\hline 80 & 74 & 274 & 307 & 74 & 5,3 & 0,85 & 6,06 \\
\hline 120 & 228,5 & 428,5 & 467,6 & 228,5 & 7,8 & 1,52 & 5,11 \\
\hline
\end{tabular}

Tabel 3. Hasil perhitungan R407C.

\begin{tabular}{|c|c|c|c|c|c|c|c|}
\hline \multirow{2}{*}{$\begin{array}{c}\text { Flowrate } \\
(\mathrm{L} / \mathrm{h})\end{array}$} & \multicolumn{4}{|c|}{ Entalpi (Kj/kg) } & \multirow{2}{*}{$\begin{array}{c}\text { Efek } \\
\text { refrigerasi } \\
\mathrm{m}_{\mathrm{r}}\left(\mathrm{h}_{2}-\mathrm{h}_{1}\right)\end{array}$} & \multirow{2}{*}{$\begin{array}{c}\text { Daya } \\
\text { kompresor } \\
\mathrm{m}_{\mathrm{r}}\left(\mathrm{h}_{3}-\mathrm{h}_{2}\right)\end{array}$} & \multirow{2}{*}{$\mathrm{COF}$} \\
\hline & $\mathrm{h}_{1}$ & $\mathrm{~h}_{2}$ & $\mathrm{~h}_{3}$ & $\mathrm{~h}_{4}$ & & & \\
\hline 20 & 235 & 444 & 475 & 235 & 1,25 & 0,18 & 6,7 \\
\hline 40 & 236 & 434 & 484 & 236 & 2,37 & 0,6 & 3,9 \\
\hline 80 & 242 & 436 & 486 & 242 & 4,7 & 1,27 & 3,8 \\
\hline 120 & 242 & 435 & 487 & 242 & 6,94 & 1,87 & 3,7 \\
\hline
\end{tabular}

Grafik hasil perhitungan dapat dilihat pada gambar di bawah ini:

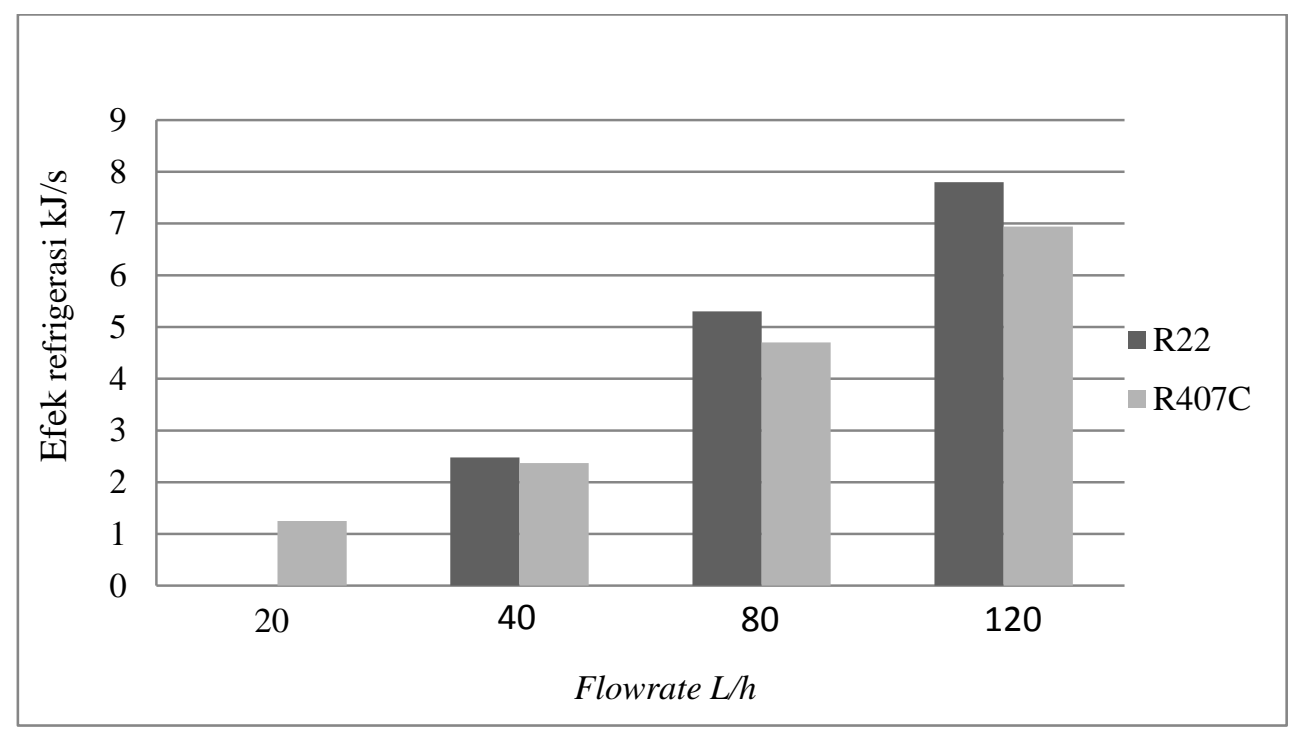

Gambar 4. Perbandingan efek refrigerasi dengan flowrate.

Gambar 4 menunjukkan kenaikan efek refrigerasi berbanding lurus dengan kenaikan flowrate pada kedua jenis refrigerant. Besar efek refrigerasi yang dihasilkan oleh refrigeran R22 lebih besar daripada refrigeran R407C. Jadi, besar panas yang diserap refrigerant R22 lebih besar dari refrigerant R407C.

Gambar 5 menunjukkan kenaikan besar daya kompresor berbanding lurus dengan kenaikan flowrate refrigerant. Besar daya kompresor yang dibutuhkan pada refrigerant R407C lebih besar dari refrigerant R22. Jadi, kinerja kompresor harus lebih besar agar refrigeran R407C dapat bekerja dengan efisien pada system. Pada proses pengambilan data, besar kuat arus listrik yang digunakan 
pada refrigeran R407C juga mengalami peningkatan dibandingkan kuat arus listrik pada refrigerant R22.

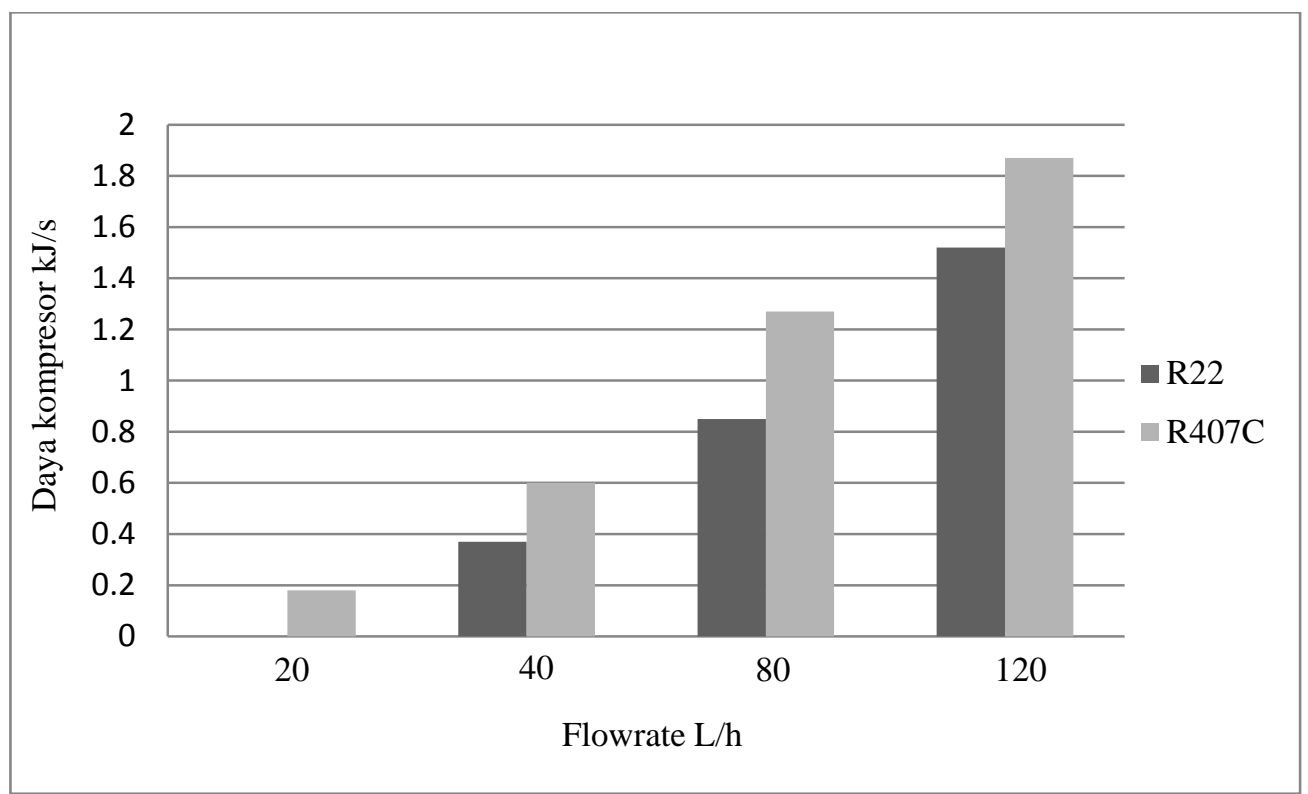

Gambar 5. Perbandingan daya kompresor dan flowrate.

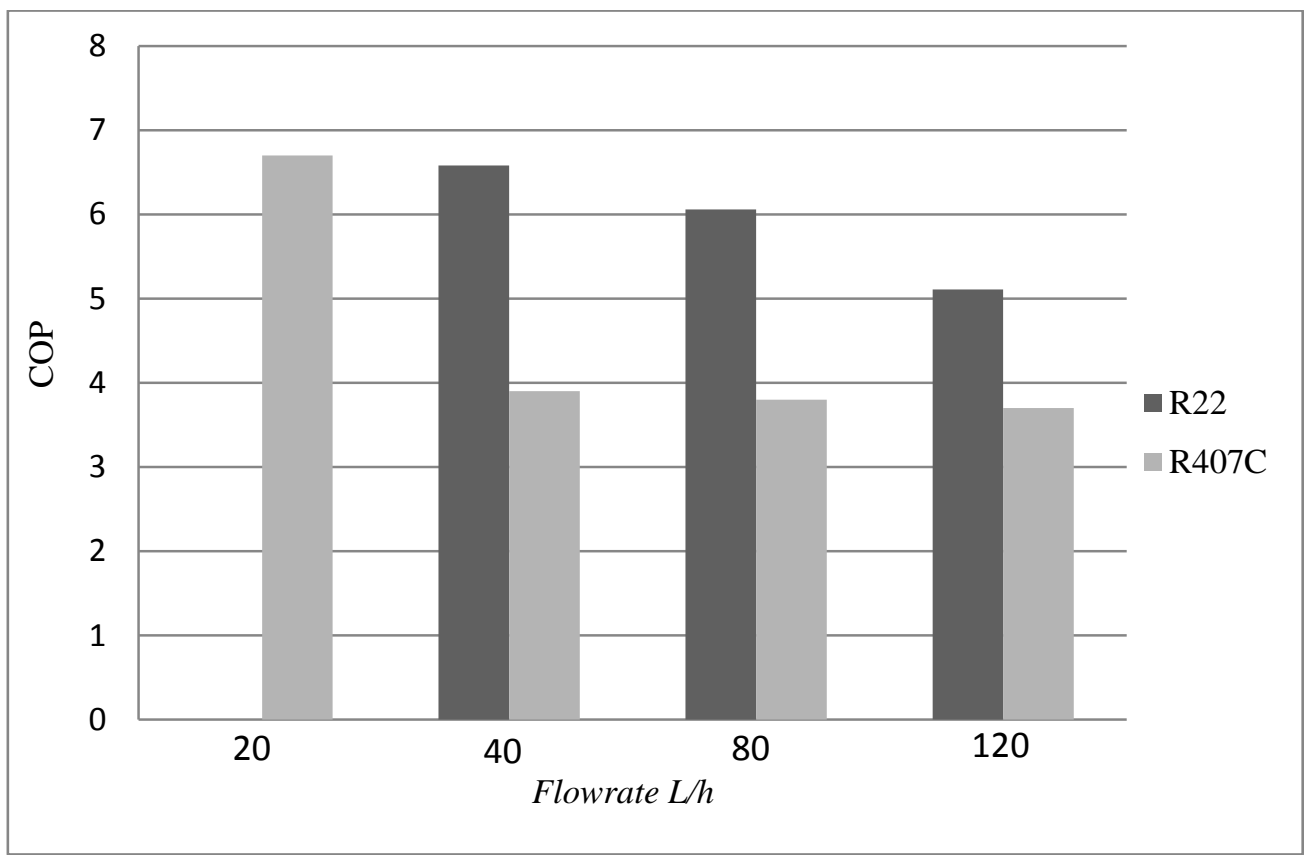

Gambar 6. Perbandingan nilai COP dan Flowrate.

Gambar 6 menunjukkan besar nilai COP refrigeran R22 pada flowrate $40 \mathrm{~L} / \mathrm{h}$ sampai $120 \mathrm{~L} / \mathrm{h}$ lebih besar dari nilai COP R407C. sedangkan pada flowrate $20 \mathrm{~L} / \mathrm{h}$ nilai COP R407C lebih besar dari R22. Hal ini disebabkan karena aliran refrigeran yang kurang sehingga terjadi kondisi vakum pada tekanan P1 dan P2. Hal yang sama juga terjadi pada efek refrigerasi dan daya kompresor. Penurunan nilai COP berbanding terbalik dengan besar flowrate. Secara keseluruhan perfoma refrigeran R22 lebih baik dari R407C berdasarkan efek refrigerasi dan daya kompresor yang dibutuhkan. 


\section{KESIMPULAN DAN SARAN}

Mesin pendingin dengan kondensor air coolant yang menggunakan refrigerant R22 menghasilkan perfoma yang lebih baik dari refrigerant R407C. Hal ini ditunjukkan pada Gambar 4 yaitu coefisien of perfomance dari refrigerant R22 lebih besar dari R407C. Besar coefisien of performance dipengaruhi oleh nilai daya kompresor yang lebih besar dari nilai efek refrigerasi. Sehingga refrigerant R407C berpendingin air coolant membutuhkan daya kompresor yang besar untuk mengompres refrigerant kedalam system pendinginan. Sedangkan refrigerant R22 berpendingin air coolant mengalami kondisi vakum pada flowrate $20 \mathrm{~L} / \mathrm{h}$. Kondisi vakum tersebut disebabkan karena kurangnya aliran refrigerant didalam system sehingga pada tekanan $\mathrm{P}_{1}$ dan $\mathrm{P}_{2}$ (sebelum dan sesudah evaporator) bernilai minus. Kurangnya aliran refrigerant mempengaruhi kinerja kompresor yang bekerja pada batas minimum. Begitu pula pada kinerja kompresor yang melewati batas maksimum dapat mengakibatkan kompresor drop dan system tidak dapat berjalan. Sehingga pada flowrate $20 \mathrm{~L} / \mathrm{h}$ refrigerant R22 berpendingin air coolant bernilai nol dan Kinerja system tidak dapat digambar pada diagram p-h. Besar flowrate yang diatur mempengaruhi nilai efek refrigerasi dan daya kompresor. Semakin besar flowrate yang diatur semakin besar efek refrigerasi dan daya kompresornya.

Menurut saya sebaiknya dilakukan pengujian terhadap beberapa jenis refrigerant pengganti yang mempunyai persamaan dengan refrigerant R22 agar lebih ramah lingkungan. Pemilihan jenis refrigerant yang membutuhkan kuat arus lebih kecil dari refrigerant R407C. menstabilkan mesin pendingin yang dipakai agar dapat bekerja maksimal pada jenis refrigerant selain R22.

\section{DAFTAR PUSTAKA}

[1]. Vaisman, I. B., "Computational Comparison of R22 and R407C Air Conditioners with Rotary Vane Compressors" (1998).

[2]. International Refrigeration and Air Conditioning Conference. Paper 382.

[3]. D.R. Wulfinghoff., “compression cooling” Reference Note 32 (1999).

[4]. Wilbert F. Stoecker, Jerold W. Jones, Supratman Hara., "Refrigerasi dan Pengkondisian Udara” Jakarta: Erlangga, 1989.

[5]. Wang, Shan K., "Handbook of air conditioning and refrigeration” McGraw-Hill Companies : 2000.

[6]. Saber Z. barandag, M. Naghash zadegan, R. hashemi., ” Performance Comparison of R407C and R22 in off-design Point Using Wilson-Plot Method” Islamic Azad University, 2011.

[7]. Bukola Olalekan Bolaji, Zhongjie Huan.,"'Computational Analysis Of The Performance Of Ozone-Friendly R22 Alternative Refrigerants In Vapour Compression Air-Conditioning Systems” Environment Protection Engineering : 2012.

[8]. Anders J., "Replacement of R22 in existing installations experiences from the Swedish phase out” Royal Institute of Technology S-100 44 Stockholm Sweden : 2003. 